\title{
A política pública LGBT na agenda dos governos PT no Brasil: Tensões entre o "ineditismo" e a política conciliatória
}

\author{
LGBT public policy on the agenda of PT governments in Brazil \\ Tensions between "originality" and conciliatory politics
}

\begin{abstract}
Bruna Andrade Irineu*
Resumo: O artigo examina a formulação da política pública LGBT no Brasil entre os anos presidenciais de Lula e Dilma. Reflete-se sobre a agenda anti-homofobia na política externa de direitos humanos destes governos, afirmando que estas iniciativas advêm da pressão dos movimentos sociais, mas, também, de um agendamento dos organismos internacionais. Analisa-se documentos oficiais do governo federal publicados entre 2003 e 2016, além de entrevistas e observações realizadas em espaços de negociação da política LGBT. O estudo se desenvolve a partir da agenda federal dos governos PT, atentando-se ao fato do esgarçamento da política conciliatória do PT estar imbricada no processo de blindagem da democracia. Assim, destaca-se que as ações neoliberais de promoção da "participação LGBT" e da "cidadania LGBT", naquele contexto político, são criticadas enquanto produtoras de homonacionalismo, do mesmo modo que a baixa efetividade e institucionalização da política LGBT são indicadores da homofobia cordial explícita na política de conciliatória.
\end{abstract}

Palavras-Chave: LGBT; Democracia; Direitos Humanos; Homofobia; Homonacionalismo.

Abstract: This paper examines the formulation of LGBT public policy in Brazil between the presidential years of Lula and Dilma. It reflects on the anti-homophobia agenda in the foreign human rights policy of these governments, stating that these initiatives come from pressure from social movements, but also from an agenda-setting by international organizations. It analyzes official documents from the federal government published between 2003 and 2016, in addition to interviews and observations carried out in spaces for negotiating LGBT politics. The study develops from the federal agenda of PT governments, paying attention to the fact that the fraying of PT's conciliatory policy is intertwined in the process of shielding democracy. Thus, it is highlighted that neoliberal actions to promote "LGBT participation" and "LGBT citizenship", in that political context, are criticized as producers of homonationalism, in the same way that the low effectiveness and institutionalization of LGBT policy are indicators of homophobia cordiality in the conciliatory policy.

Key words: LGBT; Democracy; Human rights; Homophobia; Homonationalism.

\footnotetext{
* Professora do Departamento de Serviço Social e do Programa de Pós-Graduação em Política Social na Universidade Federal de Mato Grosso - UFMT.
} 
Introdução

A pressão dos movimentos LGBT (Lésbicas, Gays, Bissexuais, Travestis e Transexuais) e feministas, as mudanças epidemiológicas (epidemia da Aids e queda na taxa de fecundidade) e demográficas (crescimento da população idosa) justificam o aumento do interesse no debate sobre gênero e sexualidade por parte da gestão pública governamental no início dos anos 2000. O avanço destas pautas na esfera pública foi determinante para os contra-ataques de setores conservadores, que já em meados desta mesma década organizavam-se no Legislativo para barrar projetos pró direitos sexuais e reprodutivos e propor leis que retrocedem a equiparação de direitos às pessoas LGBT e mulheres. Quase quinze anos depois, o atual contexto de ofensiva antigênero no Brasil é intensificado com processo eleitoral que levou Jair Bolsonaro à presidência do país. Em menos de um ano de governo, Bolsonaro tem aprofundado sua programática antigênero destituindo os conselhos de direitos, atacando as universidades públicas e o fomento às pesquisas, e investido na regressão dos direitos trabalhistas a partir da contrarreforma da previdência.

Embora não seja foco deste artigo, tal conjuntura resulta da intensificação de processos que vem desde o período da Constituinte brasileira, mas que se evidenciam com as estratégias de conciliação da gestão federal petista no Brasil, momento político que este trabalho atenta a refletir. Analisa-se as políticas públicas para população LGBT no período da gestão federal de Lula (2003-2010) e Dilma (2011-2016), observando de que modo o suposto "ineditismo" das iniciativas formuladas operaram articuladas à agenda dos organismos internacionais e a política externa de direitos humanos.

Este texto constitui-se extrato de pesquisa, que buscou compreender a dinâmica entre Estado e Sociedade Civil na arena de disputas pelos direitos destes segmentos sociais, combinando diferentes técnicas de coleta de dados: a) observação participante nas reuniões do Conselho Nacional LGBT (2011-2013) e em eventos da agenda do movimento LGBT; b) análise documental de atas, moções, resoluções e notas públicas produzidas pela área da política nacional LGBT e por grupos de ativismo; c) entrevistas com ativistas não vinculados a redes de militância; d) entrevistas com gestoras/es que atuaram nas políticas públicas durante o período recortado na pesquisa. 
Ao tratar da temática LGBT, faz-se necessário compreender as determinações de orientação sexual e identidade de gênero reconhecendo que as mesmas se particularizam especialmente nos aspectos da homofobia, também nomeada por LGBTfobia ou homolesbotransfobica. A homofobia tem sido a categoria teórica e política utilizada para designar a lógica que objetiva desumanizar o outro e torná-lo inevitavelmente diferente (BORRILLO, 2010), partilhando da hostilidade e inferiorização que outras formas de violência também se caracterizam.

Embora argumente neste texto sobre as contradições da política pública LGBT na gestão do Partido dos Trabalhadores (PT), adianto que, inegavelmente, tal política contribuiu na construção de uma "agenda anti-homofobia" (FERNANDES, 2011). Esta agenda existe e a evidência de sua existência está tanto nas respostas conservadoras que recebe quanto no espaço que este debate alçou na paradoxal política externa de direitos humanos do governo. O Programa Brasil Sem Homofobia - BSH (2004), o I Plano Nacional de Promoção dos Direitos Humanos e Cidadania LGBT (2009) e o Sistema Nacional de Enfrentamento a Violência LGBT (2013), embora criados através destas iniciativas que colocaram a LGBTfobia na agenda pública brasileira, demonstram o quanto as formulações do Executivo dependem de vínculos com marcos legais.

A ausência de um aparato jurídico-legal no âmbito dos direitos LGBT no Brasil reforça o cenário de ineficiência do Estado em incorporar as demandas jurídicas de lésbicas, gays, travestis e transexuais. A não absorção das pautas LGBT pelo Poder Legislativo gerou investimentos do movimento LGBT junto ao Poder Executivo, pressionando para formulação de políticas públicas, e também um investimento posterior em ações coletivas e individuais junto ao Poder Judiciário, como: a Ação Civil Pública (do Ministério Público Federal) contra o Instituto Nacional de Seguridade Social (INSS), no ano de 2000, cujo objetivo era a extensão dos benefícios de pensão por morte e auxílio-reclusão aos casais homossexuais; Ação Direta de Inconstitucionalidade (ADIn) e Arguição de Descumprimento de Preceito Fundamental (ADPF), que culminaram nas decisões, no ano de 2011, do Superior Tribunal Federal (STF), e, posteriormente, do Superior Tribunal Judiciário (STJ), quanto à questão da união civil entre pessoas do mesmo sexo e da possibilidade de conversão para casamento civil em todos os cartórios de registro civil do país. 
Esses avanços, portanto, sofrem com a instabilidade da ausência de um marco legal constitucional agravados pelo atual contexto de imunização do Estado às pressões populares, implantadas no decurso das gestões Lula e Dilma, cuja culminância se deu no impeachment articulado a um "golpe jurídico-parlamentar" que instituiu o governo Temer. Vale ressaltar que este processo político que o país vivencia hoje foi produto do desgaste da política conciliatória e reformista adotada pela programática petista que transitou de um projeto de "pacto social" a um projeto de "concertação social", que contribuiu para a “blindagem do regime democrático-liberal" (DEMIER, 2017).

\section{As metamorfoses do PT, o Lulismo e seu impacto na agenda LGBT}

Os primeiros grupos organizados do movimento LGBT datam do final da década de 1970 e também se articulam à história da redemocratização do país. Ao refletir sobre a formação do grupo Somos, ao final da década de 1970, Green (2014) retoma a cisão que ocorreu no grupo em face de uma possível cooptação pelo movimento sindical por militantes do grupo que compunham a Convergência Socialista. Essa, no entanto, foi a única organização de esquerda que apresentou um documento que criticava a discriminação aos homossexuais - a "Facção Homossexual" - programa que, embora simplista na avaliação de Green, foi, por ele mesmo, considerada avançada para época, no qual destaca-se o apoio ao PT:

[...] VI - Pelo apoio ao Partido dos Trabalhadores como primeiro passo para o governo dos trabalhadores

VII - Por um governo dos trabalhadores que leve a um Brasil socialista

VIII - Por um Brasil socialista onde todas as formas de exploração e opressão sejam eliminadas (OKITA, 1981 apud GREEN, 2014, p.194-195).

Observa-se ainda nesta citação que a Facção Homossexual da Convergência Socialista, assim como grande parte da esquerda brasileira, endossou o projeto inicial do Partido dos Trabalhadores (PT). Contudo, embora existisse uma militância homossexual no PT, não houve uma adesão por todos os setores do partido (GREEN, 2014). Registra-se que apenas em 1992 é que se criou em São Paulo o primeiro Núcleo LGBT do PT, tendo o Setorial Nacional LGBT sido criado somente em 2010. A partir da eleição de 2002 até as eleições de 2014, se percebe um crescimento nas candidaturas LGBT que assumiram compromisso com 
as demandas do segmento, onde majoritariamente pleiteiam o cargo de vereador/a $(89,1 \%)$, sendo o PT aquele com maior parte das candidaturas (19,8\%) (AUTOR).

A aliança histórica entre ativismo LGBT e PT impactaram no processo de formulação da política LGBT, especialmente no que tange a priorização do diálogo com determinados grupos de ativismo nacional por parte do governo e a hipervalorização na avaliação do movimento sobre a gestão da política pública de Lula. Essa visão do governo Lula como uma gestão pró-LGBT, proeminente em alguns setores da militância LGBT, especialmente por setores do ativismo LGBT alinhados à programática do partido, esconde uma perspectiva paternalista que, em minha análise, contribuiu para a baixa institucionalização da política LGBT no Brasil. Um ativista líder de uma associação nacional apontou em seu discurso que Lula seria "um herói", "gente boa" e o "Papai Noel dos gays"1". A publicação do Plano LGBT, em meados de 2009, a criação de uma Coordenação LGBT enquanto área da política na Secretaria de Direitos Humanos (SDH) e a publicação do edital para o Conselho Nacional LGBT (CNCD-LGBT), em dezembro de 2010, seriam, naquele momento, os "presentes" do "Papai Noel dos gays" na visão do ativista. O que ilustra nosso argumento de que o "paternalismo" recorrente do lulismo foi fundamental para a baixa institucionalização da política pública destinada a população LGBT.

A criação da Coordenação Nacional LGBT exigiu a indicação de alguém que viesse a ocupar o cargo no ministério, o que foi alvo de disputas entre militantes vinculados ao PT e à $A B G L T^{2}$, situação recorrente durante toda gestão Lula e Dilma. Ricci (2010) afirma que lideranças dos movimentos sociais urbanos assumiram tarefas na gestão do PT alterando sua prática e agenda. A rua "foi trocada pelas conferências e reuniões em gabinetes governamentais. Sinal de democracia. Porém, esta intimidade com a lógica pública não foi suficiente para alterar o verticalismo e fragmentação da burocracia estatal” (p.10).

Alguns setores do movimento LGBT criaram uma relação pouco contestadora acerca das metamorfoses que conduziram o PT a um distanciamento do projeto democrático

\footnotetext{
${ }^{1}$ Matéria intitulada "Em cerimônia no Planalto, Lula é chamado de 'Papai Noel dos gays'”, publicada pelo G1 em 15/12/2010. Link: http://g1.globo.com/politica/noticia/2010/12/em-cerimonia-no-planalto-lula-echamado-de-papai-noel-dos-gays.html. Acesso em 15/12/2010.

${ }^{2}$ A Associação Brasileira de Gays, Lésbicas, Bissexuais, Travestis e Transexuais é uma rede nacional, criada em 1994, com intuito de congregar grupos e ONG's LGBT regionais. Durante os governos Lula e Dilma, a ABGLT teve estreito diálogo e parceria com o governo. Atualmente, sua diretoria executiva é liderada, pela primeira vez, por uma ativista travesti, e se distingue daquela comandada por um ativista gay no período da gestão PT.
} 
popular (AUTOR). As teses para as metamorfoses do PT são muitas entre intelectuais e militantes a ele vinculados, como também o são entre aqueles que foram e deixaram de estar ligados ao partido.

Singer (2012) utiliza-se do conceito de subproletariado referenciando a uma "sobrepopulação superempobrecida" que constituiria a classe trabalhadora e comporia metade da população economicamente ativa. Entre essa fração de classe haveria, a partir de 2006, um encontro com a liderança Lula, e, "na invenção lulista da plataforma com que sempre sonhara, um Estado capaz de ajudar os mais pobres sem confrontar a ordem" (SINGER, 2012, p.67). As mudanças do PT são vistas metaforicamente a partir de uma alusão a duas almas que refletiriam uma síntese contraditória. Haveria o "espírito de Sion", aquele vinculado a um projeto nacional-popular com interesses anticapitalistas, e o "espírito do Anhembi", alinhado às intenções aprovadas pelo Diretório Nacional na campanha de 2002, com um acordo expresso com o capital observáveis na "Carta Aberta ao Povo Brasileiro3".

Para lasi (2006), o PT ousou, incomodou e transgrediu, mas não superou a velha ordem quando o partido começa a amadurecer, num momento no qual a classe trabalhadora está sendo derrotada mundialmente por meio da "ação do capital em sua reestruturação produtiva" e da erosão dos blocos socialistas. Assim, ele localiza o início da crise do projeto democrático popular após a derrota para Collor, em meados dos anos 1990. As perdas no campo prático tornaram-se "consciência da impossibilidade da ruptura". lasi (2006) tem como argumento central para essa metamorfose a ideia de que, se o proletariado integra o capital, "ele também pode se integrar moderadamente ao sistema e os esforços da burguesia caminham neste sentido" (p.547). O PT adere à "ilusão" socialdemocrata de que seria possível aliar mercado e distribuição de riquezas.

Ricci (2010) afirma que o PT passa a trabalhar pela construção de um bloco de poder com interesses eleitoreiros a partir de 1994, com a ascensão de José Dirceu ao diretório nacional. Das disputas de valores e da cultura, em ações nas ruas, o partido focou no campo institucional e eleitoral. Em consonância, Vieira (2015) também identifica que com o tempo o PT se tornou propriedade da "elite partidária", subordinando-se à ascendência de

\footnotetext{
${ }^{3}$ Cabe aqui apontar que a Carta traz a futura programática de governo de Lula para as eleições de 2002. Vieira (2015, p.706) afirma que, depois dela, no empresariado e nas elites econômicas brasileiras "não mais se teve medo do PT".
} 
parlamentares, tornando-se uma "máquina eleitoral" (p.707). Nesta linha reflexiva, Ricci (2010) denomina de "Lulismo" o modelo de gerenciamento do Estado brasileiro, no sentido de ir além de Lula, ressaltando o projeto de gestão do PT.

É a relação "[d]o surgimento do lulismo e [com] a mutação dos movimentos sociais brasileiros - (que) nascem sob o mesmo signo e motivação", que definirá o lulismo, finalizando, assim, a modernização conservadora, ou, no sentido gramsciano, a revolução passiva, pelo alto, iniciado no governo de Getúlio Vargas através de um "pacto social pelo desenvolvimentismo caracterizado pela conciliação de interesses". (RICCl, 2010, p.9)

A "política de alianças" efetivada pelo partido (VIEIRA, 2015) reafirma a ambivalência e a contradição desta política a qual a inclusão pelo consumo define sua relação com a base social - uma integração através da tutela do Estado -, denotando o seu conservadorismo. A implantação de uma agenda estatal-desenvolvimentista, aos moldes de um fordismo à brasileira, se dá pela particularidade de os movimentos sociais emergidos na década de 1980 se relacionarem com Estado em espaços de formulação de políticas públicas, com presença forte de lideranças sociais no interior deste governo (RICCI, 2010).

Fernandes (2011) teceu uma divisão analítica da gestão Lula em dois núcleos. O econômico da programática petista foi gerido por elites políticas consolidadas no legislativo, enquanto o núcleo social foi gerido por elites políticas da sociedade civil organizada. Fernandes (2011) aponta ainda que foi o núcleo social que reuniu as políticas de equidade das duas primeiras gestões petistas, destacando entre elas a "agenda anti-homofobia". No percurso da política LGBT, gradativamente essas intelectuais feministas e LGBT representantes deste "núcleo social" foram vivenciando disputas internas com a "agenda anti-LGBT e anti-aborto" dos grupos conservadores articulados ao fundamentalismo religioso (AUTOR). O que se ampliou no governo Dilma, prelúdio anunciando desde as disputas eleitorais de 2010.

Demier (2017) interpreta tais arranjos como um processo de privação das demandas populares por ampliação de direitos, com corte reformista e que determinou o atual contexto onde os grupos minoritários acabaram "tornando-se praticamente órfãos de representatividade nas instituições do regime" (p. 63) democrático.

\section{Agenda anti-homofobia na política externa do governo Lula}


Em uma mesa que reuniu dez ativistas latino-americanos na primeira conferência nacional LGBT, em 2008, as/os ativistas demonstravam em suas falas a "alegria" e o quanto a realização da conferência seria uma "lição a ser seguida" pelos outros países (BRASIL, 2008). Um ativista gay brasileiro falou do cenário que se inaugurava com a realização daquela Conferência Nacional (BRASIL, 2008, p. 66):

Eu acho que o compromisso do Presidente Lula, assumido ontem aqui, inaugura um novo tempo para nós. Inaugura um novo tempo para América Latina. Inaugura um novo tempo para a luta dos Direitos Humanos da Comunidade GLBT no âmbito internacional.

A fala demonstra a compreensão de que o governo de Lula teria inaugurado uma "escuta" das demandas do movimento LGBT, enquanto o discurso de Lula, ao apresentar um cenário de negociações a serem feitas para concretização das propostas aprovadas nas conferências, ainda na abertura do evento, ancora-se na ideia de "corresponsabilidade" e de valorização da conciliação. Sinaliza, ainda, um caráter policialesco na dinâmica da participação social, quando menciona a necessidade de uma "relação companheira", indicando que sua gestão governamental possuiu uma característica "participacionista". Esta concepção refuta análises que acreditam em uma postura do governo Lula "pura" e beneficamente "pró-LGBT".

A imagem internacional do Brasil na área LGBT, durante o governo Lula, foi moldada pelo discurso participacionista endossado pela militância LGBT brasileira que circulou nos fóruns internacionais LGBT e de HIV/Aids. A participação da Coordenação Geral LGBT da SEDH em eventos realizados para intercâmbio de experiências de cooperação internacional com a União Europeia e com o governo da Colômbia, iniciadas em 2010, também contribuíram para tal cenário. A publicação do BSH e a realização da I Conferência Nacional alocaram o Brasil no roll dos países progressistas e promotores dos direitos LGBT. Destaco a cooperação internacional firmada entre Brasil e Bogotá para troca de experiências na área LGBT, cujos encaminhamentos centraram-se no empenho em cooperar para criação de um plano aos moldes brasileiros.

\footnotetext{
${ }^{4}$ Participacionismo trata-se do conceito teórico que explica o discurso de participação social, recorrentemente utilizado no lulismo, enquanto pilar central de consolidação do ordenamento das formas de "ser e existir no interior do Estado" (MACHADO, 2013, p.170).
} 
De modo geral, a política externa de direitos humanos no governo Lula é apresentada no balanço de Asano e Nader (2011) como aquela que ampliou o protagonismo internacional brasileiro. Com esta ampliação exitosa nas relações internacionais, o governo Lula se relacionou com países de regimes democráticos e não democráticos, incluindo países violadores de direitos fundamentais de cidadania como Sudão, Irã, Coréia do Norte e GuinéEquatorial. É necessário questionar o lugar que os direitos humanos tiverem no estreitamento com esses países. Observando as posturas e os discursos do governo Lula, Asano e Nader (2011, p.119) destacam que é notório que "a proteção dos direitos humanos nem sempre prevaleceu em tais relações ${ }^{5 "}$ (ASANO e NADER, 2011, p.119).

Ciconello (2011) levantou os recursos executados nas secretarias de direitos humanos, mulheres e igualdade racial durante os anos de 2003 e 2010, verificando sua "evolução". Se comparados a demais áreas do governo percebe-se quão irrisórios são esses valores. Havia, por exemplo, um "descompasso" entre os recursos destinados à políticas de promoção da igualdade e da não discriminação e àqueles dos programas de transferência de renda. Com apoio do Banco Mundial e a boa avaliação internacional, o modelo de concessão de bolsas ${ }^{6}$ ampliou-se na gestão Lula.

Percebe-se, dessa forma, que os investimentos da gestão concentraram-se nos programas de transferência de renda e na concessão de bolsas para formação profissional continuada, como também ocorreu na educação, por meio dos programas de educação continuada do Ministério da Educação (MEC). Políticas formuladas sob os auspícios de organismos internacionais, como o Banco Mundial, Banco Interamericano de Desenvolvimento (BID), Fundo Monetário Internacional (FMI) e das agências especializadas da ONU (UNESCO, PNUD, entre outras).

\footnotetext{
${ }^{5}$ O governo Lula desempenhou papel central na criação da Reunião de Altas Autoridades de Direitos Humanos (RAADH), sendo protagonista em iniciativas relacionadas aos direitos dos idosos, crianças e adolescentes, educação em direitos humanos, combate à fome e pobreza. Nesta última, tornou-se referência mundial, cumprindo os Objetivos para o Desenvolvimento do Milênio (ODM) da ONU. Embora tivesse sido ativo na Assembleia Geral e no Conselho de Direitos Humanos (CDH) da ONU, o governo Lula se posicionou de forma questionável no tratamento de violações de direitos humanos em países como a Coréia do Norte, Sri Lanka e República Democrática do Congo (ASANO e NADER, 2011).

${ }^{6} \mathrm{Na}$ área da segurança pública, o Programa Nacional de Segurança Pública com Cidadania (Pronasci) teve $54 \%$ de seus recursos previstos destinados à concessão de bolsa-formação para policiais, agentes prisionais, bombeiros e peritos criminais. Todavia, esta política não colocou a "reforma das polícias como prioridade na construção de uma política de segurança pública com cidadania" (CICONELLO, 2011, p.90).
} 
As orientações dos organismos internacionais aos países em desenvolvimento têm sido feitas com vistas a influenciar no desenho das políticas sociais, especialmente na educação e na proteção social (BRAVO e CORREIA, 2012), desde a década de 1990. Assim, cabe inferir que parcela significativa dos processos institucionais da política pública LGBT ocorreu atrelada a parcerias com essas agências internacionais. A exemplo, o texto-base e outros processos da I Conferência Nacional LGBT foram elaborados através de consultoria financiada por cooperação internacional com o Programa das Nações Unidas para o Desenvolvimento (PNUD).

Tal afirmação indica que em certa medida a política pública LGBT instituída no governo Lula não corresponde única e exclusivamente às demandas do movimento LGBT, pois foram as diretrizes internacionais que influenciaram para que sua gestão tomasse iniciativa "nunca antes" tomada "na história mundial", como destacaram as falas de alguns ativistas gays, já referidos. Outro ativista gay afirmava: "Quando a gente circula, voa internacionalmente, [...] a gente vê que o Brasil tem importância na construção de uma agenda anti-homofobia". Ele aponta que em outros países, especialmente África e Ásia, "a luta daquelas pessoas era tão diferentes", que falar do cenário brasileiro, a partir de uma avaliação negativa, ao mesmo tempo que se apresentava a existência do BSH, causava indignação aos ativistas daqueles países.

A realidade de países nos quais a homossexualidade constitui crime, levando, inclusive, à pena de morte, foi uma preocupação levantada na I Conferência Nacional através de uma moção de apoio que indicava a necessidade de o Brasil acolher LGBT condenadas/os à pena de morte como refugiadas/os (BRASIL, 2008).

Durante a gestão Lula, alguns casos de violação de direitos humanos de LGBT foram comunicados à Coordenação Geral LGBT da SEDH. Dentre eles, realço dois que ganharam projeção internacional: os casos de David Kato e de Brenda Namigadde, ambos de Uganda. $\mathrm{Na}$ época, pesquisadoras/es de circulação internacional e ativistas da All Out contataram à Secretaria, em busca de apoio a/ao ativistas de Uganda. A All Out também mobilizou assinaturas para a não deportação de Brenda à Uganda. Um dos ativistas interlocutores da pesquisa descreveu que, no caso específico de David Kato, alguns meses antes de sua morte, contatou a SDH. David precisava sair de Uganda, porque estava sendo ameaçado de morte. “Eu lembro que a Coordenação LGBT disse que estava priorizando asilo para uma lésbica de 
Uganda que estava em Londres". Foram feitas tentativas de elaboração de uma carta de apoio a David pela SDH, mas a coordenadoria alegou estar sem tradutor para tal. "Quando David Kato foi morto, você pode procurar no youtube, Obama e Hilary Clinton fazem pronunciamento falando disso". Um dos interlocutores também questiona: "De que adianta uma nota pós-morte?".

O fato de o Brasil ser um país onde não se condena por pena de morte e um país onde se evidencia a liberdade sexual em festas populares, como o carnaval (GREEN, 2007), ocasiona interpretações de uma vida homossexual sem drásticas consequências.

\footnotetext{
Apesar de [ativistas de países sul-africanos] saberem também que aqui é um país violento, porque as estatísticas de Mott, elas viajam. Porque as estatísticas do Mott, elas chegam em outros países. [...] o Grupo Gay da Bahia dizer que o Brasil é o país que mais assassina homossexuais também é complicado, porque os outros países não fazem essas estatísticas, então não existe uma matriz comparativa. (ATIVISTA).
}

Embora haja um cenário contundente de violência letal contra a população LGBT no Brasil, a existência de uma sociabilidade aberta e pública, juntamente com o que o ativista entrevistado nomeou de "explosão de políticas públicas" durante o governo Lula, alçou o país a um patamar de referência internacional na defesa dos direitos LGBT. No entanto, é importante refletir que existem países que, embora, venham se tornando referências nos direitos LGBT, ao mesmo tempo têm desenvolvido políticas de extermínio de imigrantes, povos originários e de Estados independentes, a exemplo de Israel (PUAR, 2007).

Nesse debate, Puar (2007) e Oliveira (2013), vêm utilizando os conceitos de "homonacionalismo", "pinkwashing" e "cidadania de consolação" para criticar a produção de nacionalismos de gênero e sexualidade por parte do ativismo LGBT. Em decorrência do desejo por reconhecimento de suas demandas pelo Estado, esse ativismo promove midiaticamente governos que são violentos com povos tradicionais ou imigrantes em situação de pobreza ao mesmo tempo que, por suas iniciativas pró-LGBT, normalizam as vidas das minorias sexuais por meio do acesso às instituições sociais do Estado, como as forças armadas, por exemplo. O conceito 'homonacionalismo' problematiza a compreensão de como as complexidades de "aceitação" e "tolerância" à população LGBT e suas demandas se "tornaram um barômetro pelo qual o direito e a capacidade de soberania nacional são avaliados" (PUAR, 2013, p.336) e considerados democráticos. São formas de apropriação das 
questões de gênero e sexualidade para mascarar crimes de guerra, massacres e ocupações coloniais.

O turismo gayfriendly tem ocultado o genocídio palestino por Israel, à exemplo, evidenciando o que se denominou de pinkwashing, que, em uma tradução literal, significaria "lavar de rosa". O termo é um trocadilho com whitewashing, que seria a tradução para um material similar à cal usada em paredes das construções civis (AUTOR). A palavra também faz referência à estratégia de uma campanha do ano de 2005, realizada por Israel com auxílio de publicitários estadunidenses, onde se projeta a imagem de Israel como ponto de destino internacional gay. (PUAR, 2007). A "homofobia cordial" ou "LGBTfobia cordial" vem sendo considerada o pinkwashing brasileiro. Embora, a LGBTfobia e a cordialidade sejam expressões contraditórias, demonstram a convivência pacífica entre comportamentos, demarcando uma fronteira que não deve ser ultrapassada, em que a cultura política nacional incentiva o apagamento das diferenças e a assimilação das normas sociais. (AUTOR)

Neste sentido, ao articular esses conceitos foi possível identificar a política LGBT no governo Lula como um reflexo desta LGBTfobia cordial, que reúne o discurso do participacionismo e a estratégia da política de boa vizinhança com inoperância na efetivação de ações que impactem na realidade jurídica da população LGBT. Os limites nesta relação são impostos pela fronteira entre a garantia da laicidade do Estado e a continuidade do apoio ao governo PT pelos segmentos religiosos. No que se refere ao crescimento das candidaturas de segmentos religiosos - a vontade de estar na política e a visibilidade de uma identidade coletiva a ser disputada nos processos eleitorais -, pode-se verificar que as eleições de 2010 consolidam o que vem sendo percebido desde as eleições de 2002, especialmente na disputa presidencial. O que aponto como entrave nas negociações do ativismo LGBT com o poder público na gestão petista, cujo impacto se evidenciou com maior clareza na gestão Dilma.

\section{A “cidadania LGBT" como êxito internacional no governo Dilma Rousseff}

Se o lulismo evidenciou a contradição socioeconômica da programática de governo na Carta ao Povo Brasileiro antes mesmo das eleições de 2002, afirmando compromisso com a "dívida social histórica" e com o cumprimento dos compromissos econômicos firmados pelo governo do então presidente FHC (VIEIRA, 2015), Dilma também aliou suas posições em 
um conjunto de ambivalências nas eleições de 2009. Ao assinar a Carta Aberta ao Povo de Deus, compromete-se em fazer da "família" um ponto central de seu governo e esquiva-se de questões como aborto e casamento homossexual - afirmando serem temas de decisão do Congresso Nacional -, mas também se propõe a cumprir com a continuidade das políticas de direitos humanos firmadas no governo Lula.

A disputa pelos "votos de Deus" se deu por estratégias que incluíram não apenas a conciliação entre sujeitos com trajetória histórica de oposição, mas pela pasteurização de biografias marcadas por resistência e luta contra processos autoritários, transformando-as em imagens que conciliassem a mãe e dona de casa com a mulher profissionalmente autônoma com condições de presidir uma nação.

Em seu programa de governo, a população LGBT é mencionada no eixo "Direitos humanos e proteção de homens, mulheres e jovens" afirmando a presença de discriminação com estes segmentos. Já na Carta Aberta ao Povo de Deus, referida anteriormente, Dilma afirma: "A família sempre foi e será o baluarte de uma sociedade saudável. Quanto mais estruturada é a família, menos caos social teremos". O apelo à família e ao cristianismo foi uma das formas encontradas pela candidatura de diluir o medo que a biografia da exguerrilheira causava nos setores conservadores. A postura rígida e firme de Dilma alocou-a em situações de homofobia, especialmente por parte da mídia brasileira. Quando questionada sobre sua orientação sexual, Dilma afirmou ser "avó" e "mãe", demonstrando um discurso de não reconhecimento das famílias homoparentais. A postura de Dilma nas eleições pouco se diferenciará ao ser empossada, tendo em sua gestão uma avaliação bastante distinta em relação ao seu antecessor.

Na esfera do controle social da política LGBT, por exemplo, o decreto de recriação foi publicado após as eleições de 2010, em dezembro, no último mês do governo Lula. Em uma das primeiras reuniões do conselho, um ativista gay afirmou: "Se tivessem deixado esse decreto para publicar em janeiro, esse conselho não tinha saído". A comparação entre as posturas de Dilma e Lula foi recorrente nos bastidores das primeiras reuniões do conselho, mas velada nos espaços de fala pública até a reprovação do Kit Escola sem Homofobia, em maio de 2011.

Se o discurso participacionista foi evidenciado na gestão Lula, as tensões e disputas que constituíram a gestão Dilma não descrevem um percurso de continuidade nas 
estratégias discursivas do governo federal. A criação de algumas iniciativas importantes, como o Relatório sobre Violência Homofóbica no Brasil (elaborado pela SDH) e a opção por ações que generalizavam os direitos humanos, se alternou em alguns momentos da primeira gestão Dilma.

A gestão Dilma, em seu primeiro ano, vetou o Kit Escola sem Homofobia, material educativo que o MEC produziu para as escolas, após pressão da "bancada evangélica" do Congresso Nacional, em um momento de negociação de supostos escândalos de corrupção envolvendo Antônio Palocci, declarando ela mesma que não faria propaganda de opções sexuais em seu governo (AUTOR). No entanto, no segundo ano de sua gestão, o trabalho de articulação da SDH e do CNCD-LGBT foram importantes nas questões: a) da articulação com o STF para aprovação da união estável; b) dos primeiros dados oficiais, produzidos pela SDH, de índices de homofobia no país; c) das sucessivas moções e notas públicas sobre retrocesso no congresso nacional; d) da formulação de um Sistema Nacional de atendimento e encaminhamento de denúncias de violências. Destarte, a existência de um Conselho LGBT, de um Plano Nacional e um órgão gestor da política na SDH, foram vitrine para a política externa de direitos humanos brasileira, em continuidade com a política da gestão Lula. Esses mecanismos, ainda que em minhas análises reflitam soluções tecnoburocratas frágeis e distantes de uma efetiva promoção da diversidade sexual e de gênero, se comparada a realidade de muitos países soam como uma enormidade de políticas e ações para cidadania LGBT.

Ainda assim, durante a Revisão Periódica Universal7 (RPU) da ONU, no ano de 2011, - Brasil recebeu como recomendação da Finlândia, "emendar a legislação para o reconhecimento legal de casais do mesmo sexo", e não cumpriu com o indicado. Ainda em 2011, o Brasil votou favorável a resolução sobre violação de direitos humanos LGBT aprovada pelo Conselho de Direitos Humanos da ONU. Na mesma época, ao abrir a II Conferência LGBT, a ministra Maria do Rosário também enfatizou o protagonismo internacional do Brasil na área:

\footnotetext{
${ }^{7}$ A Revisão Periódica Universal (RPU) é o mecanismo do Conselho de Direitos Humanos das Nações Unidas (CDH), que determina aos 193 Estados-membros da ONU que sejam submetidos periodicamente a uma revisão de sua situação de direitos humanos a cada quatro anos e meio.
} 
É importante valorizarmos a posição norte-americana, mas é importante dizer que a nossa embaixadora no Conselho de Direitos Humanos das Nações Unidas, Maria Nazareth, foi protagonista essencial para a aprovação, pela primeira vez no âmbito das Nações Unidas, de uma perspectiva de convenção, de condenação de atos de dimensão homofóbica, rumo a uma declaração específica dos direitos da população LGBT no mundo. O Brasil se orgulha de ter sido protagonista, com o nosso Ministério das Relações Exteriores, nesse sentido. (BRASIL, 2011, p. 23).

Em 24 de setembro de 2014, durante as eleições do segundo pleito eleitoral de Dilma, a presidenta discursou na ONU, afirmando que seu governo tem o "empenho em combater a homofobia", assim como tem feito com o racismo e a violência contra as mulheres.

O Brasil tem um reconhecimento internacional na questão dos direitos LGBT, é visto como um país, é.... pioneiro nas políticas públicas para a população LGBT, e que defende publicamente nos espaços de articulação internacional os direitos da população LGBT na OEA, na ONU, na comissão de direitos humanos da ONU. [...] o Brasil tem sido no MERCOSUL, por exemplo, junto com a Argentina o país que tem estado junto mais a linha da política mais progressista com relação a temática LGBT. A recente resolução na OEA também sobre a questão do enfrentamento da discriminação, sobre todo tipo de discriminação, inclusive diversidade sexual e de gênero também. Foi um avanço conseguirmos aprovar essa resolução, essa convenção. Foi o primeiro documento da OEA que trata desse tema, que aborda esse tema, e o Brasil foi um dos primeiros países a assinar esse documento. (GESTOR/A).

Todavia, o discurso de país defensor dos direitos humanos soou nacionalmente como discurso "para inglês ver" para alguns setores do movimento LGBT.

Eu acho que assim, como eu disse, eu acho que o Brasil vende uma imagem externamente que não condiz com a realidade que a gente vive. Isso um dia, essa máscara ela vai cair, já tem caído, já tem saído notícias em vários jornais, de vários países do tipo "Olha, não é bem assim". Então assim, ou eles começam a conduzir a política LGBT dentro do país do jeito que eles querem que saiam nos jornais lá fora ou, então, não adianta fazer propaganda de uma coisa que não acontece (ATIVISTA).

Um conjunto de ações nomeado pela SDH e parcela do ativismo LGBT de "tripé da cidadania" LGBT, habitou os discursos sobre a política de direitos humanos no campo internacional. No entanto, a concepção de cidadania neste contexto atrelava-se às ações que circundam este "tripé". O que considero como uma sedução neoliberal, já que a ideia de cidadania que partilho pressupõe outros direitos mais amplos que um documento formal da política pública, um conselho para controle social da mesma e um órgão para gestão da política. Pois essa tríade é insuficiente para definir dotação orçamentária para ações e 
tampouco sintetizam o compromisso político contra práticas de discriminação e com a construção de uma outra sociabilidade.

\section{À guisa de conclusão}

Fraser (2007) criticou, com a emergência do neoliberalismo, as táticas adotadas por parcela do feminismo europeu no final dos anos de 1970, que, segundo ela, estavam "efetivamente encantadas pela política de reconhecimento", e sem intuito "direcionamos a teoria feminista para canais culturalistas, precisamente quando as circunstâncias requeriam atenção redobrada às políticas de redistribuição" (p.297). Orientado por esta crítica, do mesmo modo, este artigo pretendeu, de igual modo, o propósito deste artigo foi desenvolver uma crítica desvelar os limites e contradições do modelo da política pública LGBT, instituído pelos governos federais do PT.

O sul global não teve um Estado de Bem Estar Social para ser revertido pelo neoliberalismo, cuja "mudança chave" esteve no crescimento agregado do comércio mundial e o impacto neoliberal para além da economia política, relacionando-a, fundamentalmente, com mudanças na vida organizacional. A ideia de cidadania LGBT circunscreve-se em reivindicações por liberdades, autonomia civis e pelo 'reconhecimento' da diferença (FRASER, 2007). O que implica em utilizar a cidadania como estratégia política, sob os auspícios de uma cidadania limitada por condições frágeis e descontínuas da política pública LGBT na gestão PT, mas, também se relacionou à crise de representatividade nos movimentos sociais, que não atinge a população usuária desta política.

Em tempos de "democracia blindada" (DEMIER, 2017) paga-se preço alto de uma luta por direitos ancorados em uma concepção de cidadania LGBT respaldada na homofobia cordial, onde acreditou-se ser possível reunir em um mesmo lado do "jogo político" Crivella, Marco Feliciano e setores do movimento LGBT. Essa concepção de cidadania é limitada especialmente a uma moral sexual imbricada no "familismo" anti-LGBT. Produzindo conquistas incompletas do campo da cidadania sexual que servem como uma "cidadania de consolação" (OLIVEIRA, 2013) exclusiva do "pink money" e do neoliberalismo.

\footnotetext{
8 Pink money é um termo para denominar a capacidade de consumo da comunidade LGBTI e a apropriação disso pelo mercado na constituição de nichos de circulação de mercadoria destinada a este segmento. $O$ uso do
} 
Faz-se saber, que enquanto esse texto era escrito, as redes sociais noticiavam a morte de uma jovem lésbica barbaramente assassinada pelo pai de sua namorada, quando ia pedi-la em casamento. Afirmo que, nas tramas do Estado, "reconhecer a violência, não garante de forma alguma uma política de não violência" (BUTLER, 2015, p. 250). Uma cidadania de consolação, uma política governamental sem orçamento, uma iniciativa descontínua, um agrupamento de documentos oficiais do Executivo ou um agendamento público da homofobia em nível internacional não garantem uma política efetiva contra a LGBTfobia.

Os efeitos perversos do Capital nas vidas da classe trabalhadora, de mulheres, LGBT, negras, imigrantes e pobres, na mesma medida em que buscam nos ceifar também produzem resistência, fazendo com que não tenhamos tempo de temer e sigamos em luta fortalecendo o pensamento crítico e a defesa de um projeto societário humanamente emancipatório.

\section{Referências}

ASANO, Camila; NADER, Lucia. "Reflexões sobre a política externa em direitos humanos do governo Lula". In: PAULA, Marilene. "Nunca antes na história desse país"...? : um balanço das políticas do governo Lula. Rio de Janeiro: Fundação Heinrich Böll, 2011.

BRASIL. Secretaria Especial dos Direitos Humanos. Anais da Conferência Nacional de Gays, Lésbicas, Bissexuais, Travestis e Transexuais. Brasília, 2008.

. Secretaria Especial dos Direitos Humanos. Anais da Il Conferência Nacional de Gays, Lésbicas, Bissexuais, Travestis e Transexuais. Brasília, 2011.

BORRILLO, Daniel. Homofobia: história e crítica de um preconceito. Belo Horizonte: Autêntica, 2010.

BRAVO, Maria Inês; CORREA, Maria Valéria C. Desafios do controle social na atualidade. Serv. Soc. Soc., São Paulo, n. 109, p. 126-150, jan./mar. 2012.

BUTLER, Judith. Quadros de Guerra: quando a vida é possível de luta? Rio de Janeiro: Civilização Brasileira, 2015.

termo por ativistas e pesquisadoras/es tem se dado na tentativa de explicar os limites da cidadania liberal e as hierarquias de raça e classe social as quais LGBTI também estão submetidos na realidade social. 
CICONELLO, Alexandre. Os avanços e contradições na política de direitos humanos do Governo Lula. In: PAULA, Marilene. "Nunca antes na história desse país"...? : um balanço das políticas do governo Lula. Rio de Janeiro: Fundação Heinrich Böll, 2011.

DEMIER, Felipe. Depois do Golpe: a dialética da democracia blindada no Brasil. Rio de Janeiro: Mauad X, 2017.

FERNANDES, Felipe B. M. "A agenda anti-homofobia na educação brasileira (2003-2010)". Tese de Doutorado Interdisciplinar em Ciências Humanas. Florianópolis: UFSC, 2011.

FRASER, Nancy. "Mapeando a imaginação feminista: da redistribuição ao reconhecimento e à representação". In: Revista de Estudos Feministas. [online]. 2007, vol.15, no2, p.291-308. ISSN 0104-026X. http://dx.doi.org/10.1590/S0104-026X2007000200002.

GREEN, James N. "O grupo Somos, a esquerda e a resistência à ditadura". In: GREEN, James N.; QUINALHA, Renan. Ditadura e homossexualidade: repressão, resistência e a busca da verdade. EDUFSCar: São Carlos, 2014.

IASI, Mauro L. As metamorfoses da consciência de classe: o PT entre a negação e o consentimento. São Paulo: Expressão Popular, 2006.

MACHADO, Frederico V. Do estatal à política: uma análise psicopolítica das relações entre o Estado e os movimentos de juventude e LGBT no Brasil (2003-2010). Tese de Doutorado em Psicologia. Belo Horizonte: UFMG, 2013.

OLIVEIRA, João M. "Cidadania sexual sob suspeita: uma meditação sobre as fundações homonormativas e neo-liberais". In: Psicologia \& Sociedade; 25(1), 2013, p.68-78.

PUAR, Jasbir. Terrorist assemblages: homonationalism in queer times. Durham, N.C.: Duke University Press, 2007.

RICCI, Rudá. Lulismo: da era dos movimentos sociais à ascensão da nova classe média Brasileira. Rio de Janeiro: Editora Contraponto, 2010.

SINGER, André. Os sentidos do lulismo: reforma gradual e pacto conservador. São Paulo: Cia. das Letras, 2012.

VIEIRA, Evaldo. A República brasileira 1951-2010: de Getúlio a Lula. São Paulo; Cortez, 2015. 